\title{
WORKSHOP PENGAYAAN MATERI PRAKTIK KERJA INDUSTRI BAGI SISWA SMK ANCOP DESA KAWALELO
}

\author{
Lyly Soemarni' ${ }^{1}$, Ringkar Situmorang ${ }^{2}$, Andi Guna ${ }^{3}$, \\ Aryaning Arya Kresna ${ }^{4}$, Donny Erick Pioh ${ }^{5}$ Casey Eve Angelique ${ }^{6}$ \\ Program Studi Pariwisata Institut Sains dan Teknologi Pradita \\ lyly.soemarni@pradita.ac.id, ringkar.situmorang@pradita.ac.id, andi.guna@pradita.ac.id
}

\begin{abstract}
Abstrak
Pendidikan vokasi menjadi perhatian pemerintah dalam upaya meningkatkan sumber daya manusia agar memiliki keterampilan dan daya saing yang baik. Pendidikan vokasi seperti sekolah menengah kejuruan memiliki program praktik kerja industri (Prakerin) selama 2 bulan untuk memberikan pengalaman kerja dan penerapan pengetahuan dan keterampilan bagi siswanya. SMK ANCOP melihat adanya kebutuhan pembekalan lebih dalam bagi siswa-siswinya yang mengikuti program praktik kerja industri pada biro perjalanan wisata di Jakarta sekitarnya. Kegiatan pengabdian kepada masyarakat ini dilaksanakan selama 7 hari dan melibatkan program studi Pariwisata, Sistem Informasi dan Manajemen Bisnis Perjalanan (STP Bandung) dengan tujuan memberikan pengayaan materi keterampilan terkait dengan bidang kerja dan meningkatan kemampuan intra dan interpersonal (soft skill). Metode yang digunakan untuk materi keterampilan melalui praktikum di laboratorium komputer untuk penggunaan global informasi seperti Computer Reservation System, penelusuran informasi melalui mesin pencari, praktik pemanduan di TMII sedangkan untuk materi soft skill melalui paparan dan diskusi dalam kelas. Hasil dari kegiatan ini berupa kumpulan tugas mandiri yang dapat memperlihatkan kemampuan dan keterampilan dari masing-masing materi pengayaan dan evaluasi tertulis dari pihak yayasan ANCOP yang menyatakan bahwa siswa-siswi SMK ANCOP dapat menjalankan tugas tanggungjawabnya selama 02 bulan dengan menunjukkan kemampuan bekerja dan mampu berinteraksi dengan rekan kerja dan beradaptasi di lingkungan baru. Manfaat dari program pengayaan ini memberikan kesempatan bagi siswa-siswi SMK ANCOP untuk memiliki pengetahuan dan keterampilan yang terkini dalam upaya menghadapi dunia kerja yang kompleks khususnya dibidang perjalanan wisata, dimana tuntutan disiplin, mandiri, inisiatif dan kemampuan beradapatsai menjadi kunci keberhasilan.
\end{abstract}

Kata Kunci: Pendidikan Vokasi, Prakerin, soft skill

\section{PENDAHULUAN}

Pendidikan Vokasi secara umum dapat didefinisikan sebagai bentuk pendidikan yang memberikan pengetahuan dan keterampilan profesional secara khusus (Kotsikis, 2007). Selain itu, pendidikan vokasi juga salahsatu dari bagian sistem strategis pendidikan nasional untuk mewujudkan tenaga kerja yang terampil dan terkualifikasi. Upaya yang dapat dilakukan adalah dengan menyediakan pelatihan-pelatihan yang dibutuhkan, membentuk kepribadian, atribut personal, dan kemampuan khusus. Penerapan pendidikan vokasi salahsatunya ada pada Sekolah Menengah Kejuruan (SMK), yang mana mereka memiliki program Praktik Kerja Industri (PRAKERIN). 
PRAKERIN adalah suatu kegiatan pendidikan dalam bentuk pelatihan dan pembelajaran langsung di industri atau dunia kerja nyata yang diikuti oleh siswa/siswi SMK. Prakerin memiliki upaya meningkatkan partisipasi siswasiswi SMK dalam membantu industri dan memperluas relasi di masa depan dalam menghadapi tantangan dan persaingan yang semakin ketat. Selain itu, manfaat lain dari Prakerin adalah dapat menambah ilmu-ilmu baru yang mungkin belum pernah didapatkan saat pembekalan di sekolah. Siswa/siswi SMK yang dikirim untuk Prakerin pada umumnya sudah dibekali kemampuan dasar untuk mempermudah proses pelaksanaan di industri. Untuk menghadapi persaingan, perlu adanya dukungan kemitraan dan sinergi yang kuat antara lembaga pendidikan dan pelatihan dengan industri. Melalui strategi ini diharapkan kompetensi pekerja akan terus terjaga sesuai dengan kebutuhan industri.

Data dari Kementerian Tenaga Kerja RI melalui Detik.com (2018) menyatakan bahwa jumlah tenaga kerja terampil dan bersertifikasi adalah sebanyak 1.349 juta. Walaupun demikian, jumlah yang dipersiapkan dan ditargetkan secara nasional pada tahun 2019 adalah sebanyak 1.500 juta. Sebagai contoh, di sektor pariwisata, penambahan jumlah tenaga kerja tersertifikasi ditahun 2018 yang telah dilakukan oleh Kementerian Pariwisata melalui data Bisnis.com adalah berjumlah 400.000 orang. Jumlah tersebut dianggap kurang untuk memenuhi kebutuhan industri sehingga ada target penambahan menjadi sebanyak 500.000 orang di tahun 2019. Dari data tersebut, dapat diilustrasikan bahwa kenyataan dan permintaan kebutuhan tenaga kerja di semua sektor, khususnya sektor pariwisata masih menjadi sebuah tantangan dan perlu ditingkatkan.

Kompetensi intra \& interpersonal (soft skill) dianggap penting kepada setiap tenaga kerja untuk bisa bersaing di era revolusi industri. Menanamkan pembekalan soft skill membutuhkan proses yang tidak singkat. Kompetensi ini mencakup penguatan karakter inti manusia, seperti kreatifitas, emosi, imaginasi, dan etik. Oleh karena itu, pendidikan vokasi perlu memastikan internalisasi soft skill disampaikan pada setiap pelajarnya.

Penerapan teknologi informasi dalam pelaksanaan Prakerin tidak hanya dituntut memiliki kemampuan teknis saja, tetapi siswa/siswi SMK juga harus mampu mengoperasionalkannya. Pesatnya perkembangan teknologi, membuat hampir semua industri menerapkan teknologi informasi terbaru. Hal ini bertujuan agar menunjang suatu pekerjaan menjadi lebih mudah, praktis dan cepat. Penerapan ini dapat dilihat dari banyaknya penggunaan peralatan baru dan sistem perangkat lunak (software) di hampir semua tempat praktik kerja. Oleh karena itu, siswa/siswi SMK disarankan mampu beradaptasi, lebih fleksibel, dan berwawasan luas dengan teknologi informasi.

Tujuan kegiatan pengabdian masyarakat ini adalah memberikan pembekalan dan pelatihan di bidang Usaha Pariwisata (UPW) dan Perhotelan kepada siswa/siswi SMK ANCOP di Desa Kewalelo, Kab. Flores Timur. Kegiatan ini juga Pendidikan 959 
mempunyai maksud dalam rangka mempersiapkan para siswa/siswinya menghadapi Praktik Kerja Industri (PRAKERIN) selama 2-3 bulan di suatu industri terkait. Selain pembekalan untuk individu, diharapkan para siswa setelah lulus juga dapat membangun desanya dan membuka peluang kerja seluas-luasnya bagi orang lain, khususnya di sektor pariwisata.

\section{METODE}

Kegiatan pengabdian masyarakat dikemas dalam bentuk workshop yang berjudul "Workshop pengayaan materi praktik kerja industri bagi siswa SMK ANCOP Desa Kawalelo Flores Timur". Kegiatan ini diselenggarkan pada tanggal 21 Januari s.d 31 Januari 2019 (7 hari) di laboratorium Pradita Institute untuk pengayaan materi, dan TMII untuk praktikum pemanduan. Peserta yang hadir berjumlah 10 siswa/siswi dan 2 guru pendamping. Pengabdian masyarakat ini secara internal melibatkan program studi Pariwisata, Sistem Informasi, dan Manajemen Bisnis Perjalanan (Sekolah Tinggi Pariwisata NHI Bandung) secara eksternal. Instruktur workshop diprakarsai oleh tim dosen yang terdiri dari 8 orang. Adapun 3 (tiga) metode pembekalan dan pelatihan yang digunakan antara lain; paparan \& diskusi kelas, praktikum di laboratorium komputer, dan praktikum pemanduan di TMII.

Metode paparan dan diskusi dilaksanakan di ruang kelas G03 Pradita Insitute. Ruang kelas tersebut didesain dengan konsep seperti kantor layaknya berada di dunia kerja nyata. Hal ini bertujuan agar pelajar dapat terbiasa dengan suasana industri saat ini. Selain itu, susunan meja dbentuk dengan pola $U$-Shape guna menghasilkan penyampaian materi dan diskusi yang efektif. Adapun 10 (sepuluh) topik yang diberikan sebagai materi workshop yaitu:

\section{Tabel 1. Susunan materi workshop}

\begin{tabular}{|c|c|c|}
\hline $\begin{array}{l}\mathbf{N} \\
\mathbf{0}\end{array}$ & & Materi \\
\hline & $\begin{array}{l}\text { Kebersihan dan } \\
\text { penampilan diri }\end{array}$ & $\begin{array}{l}\text { Teknik pemanduan wisata } \\
\text { dan bahan pemanduan }\end{array}$ \\
\hline & $\begin{array}{l}\text { Geografi pariwisata } \\
\text { Indonesia }\end{array}$ & 7. Praktik pemanduan wisata \\
\hline & $\begin{array}{l}\text { Kiat beradaptasi } \\
\text { dalam lingkungan } \\
\text { baru }\end{array}$ & $\begin{array}{l}\text { Penelusuran informasi nama } \\
\text { bandara \& kode kota di } \\
\text { Indonesia dan kota besar } \\
\text { dunia }\end{array}$ \\
\hline & $\begin{array}{l}\text { Pentingnya etos kerja } \\
\text { dan disiplin }\end{array}$ & 9. Reservasi penerbangan \\
\hline & $\begin{array}{l}\text { Tata Cara Makan } \\
\text { (table manner) }\end{array}$ & $10 \begin{array}{l}\text { Tarif \& dokumen pasasi } \\
\text { domestik }\end{array}$ \\
\hline
\end{tabular}

Metode praktikum dilakukan di laboratorium komputer, restoran, ruang kelas dan perpustakaan Pradita Insitute, dan Taman Mini Indonesia Indah. Laboratorium Pradita Intitute terbilang lengkap dalam memfasilitasi kebutuhan praktik, mulai dari peralatan, perlengkapan, dan ruang khusus. Misalnya, penggunaan teknologi informasi seperti Computer Reservation System, penelusuran informasi melalui mesin pencari, praktik table manner dan perhitungan biaya dokumen pasasi (tiket domestik).

\section{HASIL DAN PEMBAHASAN}


Berikut adalah hasil dan pembahasan dari proses workshop pengayaan praktik kerja industri yang bersifat paparan \& diskusi, praktik tata cara makan, praktik reservasi, perhitungan tarif dokumen pasasi (tiket domestik) dan pemandu wisata.

\section{Paparan \& Diskusi}

a. Kebersihan dan penampilan diri, para siswa/siswi diajarkan tentang pentingnya penampilan dan kebersihan pribadi di industri pariwisata. Peserta diberikan ilustrasi tentang penampilan seorang petugas yang mampu menciptakan kesan pertama (first impression) yang baik di mata para pelanggan/tamu. Pengajar juga menyampaikan tentang cara berpakaian dan standar penampilan agar menjadi pusat perhatian saat melayani tamu, seperti penampilan rambut, wajah, gigi, postur tubuh, dan sepatu.

b. Geografi pariwisata Indonesia, materi yang diajarkan mencakup pengantar dasar tentang ilmu geografi, pariwisata, dan kaitannya geografi pariwisata. Paparan mencakup tentang bagaimana lingkungan dimana manusia tinggal akan membentuk tatanan kehidupan, terbentuknya budaya, tradisi/ kebiasaan, mata pencaharian, bentuk tempat tinggal, pakaian yang dikenakan dan makanan sehari-hari. Dengan memberikan beberapa contoh destinasi pariwisata guna mendapatkan gambaran umum pengetahuan geografi pariwisata saat ini. Setelah mendapatkan pemahaman tersebut siswa diajak untuk mampu mengobservasi karakteristik sumber daya pariwisata yang ada di Indonesia. Selain itu, faktor-faktor yang mempengaruhi seseorang melakukan perjalanan wisata. Sesi diskusi diberikan untuk menguraikan pendapat tentang potensi dan karakteristik pariwisata khususnya yang ada di Nusa Tenggara Timur.

c. Kiat beradaptasi dalam lingkungan baru, pengajar mendemonstrasikan pengalamannya tentang suasana saat baru berpindah dari satu tempat ke tempat yang lain. Dimana hal-hal yang ditemukan adalah suasana baru, wajah baru, dan kepribadian teman/rekan kerja yang bervariasi. Maka dari itu, perlu disampaikannya kiat-kiat beradaptasi dalam lingkungan baru. Pertama, mereka diajarkan untuk mempersiapkan diri dan mental dengan cara tidak berasumsi bahwa lingkungan baru itu akan sulit. Kedua, siswa/siswi diajarkan untuk menghargai setiap perbedaan, karena mungkin akan ada perbedaan budaya yang di tempat baru dan kebiasaan lama di tempat sebelumnya. Ketiga, mereka diajarkan untuk aktif berinteraksi, bertanya dan meminta bantuan jika siswa/siswi menemukan kesulitan agar pekerjaan selesai sesuai dengan yang diharapkan.

d.Pentingnya etos kerja dan disiplin, materi pentingnya etos kerja dan disiplin dideskripsikan guna siswa/siswi meningkatkan rasa tanggung jawab, kepribadian, perilaku, sikap, dan karakter yang baik pada setiap masing-masing individu. Secara sederhana, mereka dilatih untuk selalu totalitas atau 
menunjukan yang terbaik dalam menjalani sebuah pekerjaan. Cara-cara yang disampaikan antara lain: selalu memotivasi diri untuk hadir dan menyelesaikan pekerjaan tepat waktu, sikap profesionalisme antara urusan pekerjaan dan luar pekerjaan, selalu bersikap positif terhadap isu-isu negatif di lingkungan organisasi, bersikap optimis dalam menjalankan semua tanggung jawab pekerjaan.

e.Teknik pemanduan wisata dan bahan pemanduan, pengajar menjelaskan materi teknik pemanduan yang dibagi menjadi 3 (tiga) tahapan; pengawalan, pelaksanaan, dan penutupan. Pertama, siswa/siswi diajarkan untuk selalu mengawali pemanduan dengan mengucapkan salam, memperkenalkan diri dan berkenalan dengan tamu, dan menjelaskan rangkaian aktifitas (itinerary) secara singkat dan jelas. Kedua, pada saat tahap pelaksanaan, mereka diajarkan untuk siap menguasai bahan pemanduan yang berisikan informasi tentang daya tarik wisata atau gambaran umum wilayah yang dituju. Selain itu, bersikap tanggap akan kondisi wisatawan yang lelah, jenuh, ataupun mengantuk. Mereka memahami peranannya ketika sedang menjelaskan objek tertentu, serta mengawasi tamu agar tidak ada yang terpencar atau menghilang dari kelompok. Ketiga, pada saat penutupan, peserta diajarkan untuk mengakhiri pemanduan di tempat/lokasi yang strategis, menarik,dan nyaman untuk memberikan kesan yang menyenangkan pada akhir tur, serta rendah hati jika ada sesuatu hal yang kurang baik.

f. Penelusuran informasi nama bandara \& kode kota di Indonesia dan kota besar dunia, sesi materi ini bersifat pembekalan pengetahuan dasar informasi nama bandara dan kode kota domestik dan internasional. Materi ini penting untuk disampaikan agar peserta mengetahui secara cepat dan tanggap saat membutuhkan informasi tersebut. Dosen pembimbing menjabarkan secara singkat dan menyeluruh tentang nama-nama bandara beserta kode kota mulai dari Sabang, Merauke, Miangas hingga Rote. Selain itu, bandara populer di beberapa negara-negara Asia, Eropa, Amerika, Australia, dan Afrika. Kuis dan diskusi diberikan guna mengingat lebih dalam hasil penelusuran pada sesi ini,

g. Reservasi penerbangan, materi dijelaskan secara teoritis seperti macam-macam reservasi tiket pesawat online dan offline, fungsi dan kode mengeja (spell) A-Z dalam sistem reservasi pesawat contohnya $\mathrm{A}=\mathrm{Alpha}$ dan seterusnya. Selain itu, jenis-jenis sistem kelas pesawat seperti First Class, Business Class, dan Economy Class. Time limit atau batas waktu cetak tiket yang sudah ditetapkan oleh maskapai. Pengenalan kode booking (PNRPasengger Name Record) guna melakukan pengecekan atau perubahan reservasi dengan kode tersebut dan pengenalan tentag reservasi ulang yang disebabkn pembatalan oleh pihak maskapai atau faktor lainnya. Pengajar juga

$$
\text { Pendidikan }
$$


menjelaskan tentang langkah-langkah melakukan reservasi langsung.

h. Tarif \& dokumen pasasi domestik, setelah pemaparan resevasi penerbangan, materi kelas disambung dengan pengetahuan umum tentang tarif dan dokumen pasasi domestik. Secara umum, peserta diajarkan hal-hal yang perlu diketahui, antara lain: istilah yang tertera dalam tiket seperti non-transferable (tiket tidak dapat digunakan orang lain), nonendorsable (maskapai tidak dapat dirubah atau pindah maskapai lain), non-refundable (tiket tidak dapat diuangkan). Selain itu, pemaparan materi juga menjelaskan tentang jenis tarif seperti nett fare dan published fare, jenis perjalanan seperti One Way (satu kali perjalanan) dan Return (perjalanan pulang \& pergi).

\section{Praktikum}

a. Praktik tata cara makan, praktik tata cara makan (table manner) diajarkan supaya siswa/siswi memahami dan mampu menyesuaikan aturan etiket secara umum ketika mereka bekerja atau sebagai tamu pada saat jamuan formal. Ada 3 (tiga) materi praktik yang diajarkan, antara lain; aturan dasar dalam etika makan, rangkaian menu, dan aturan tata letak peralatan makan. Pertama, mereka didemonstrasikan tentang aturan dasar etika makan seperti, duduk tegak di kursi, cara memegang peralatan makan, mulut tertutup saat mengunyah, menutup mulut saat bersin atau batuk, meletakan sendok arah jam 6 saat selesai makan, cara menggunakan tusuk gigi saat berada di dalam mulut, dan berbicara dengan suara rendah. Kedua, dosen pembimbing menjelaskan 3 (tiga) rangkaian menu secara umum yang perlu siswa/siswi ketahui. Rangkaian menu tersebut adalah hidangan pembuka (appetizer), hidangan utama (main course), dan hidangan penutup (dessert). Sebelum hidangan pembuka dimulai, pengajar mendemonstrasikan sajian roti di atas meja terlebih dahulu, disambung dengan hot appertizer seperti sup atau cold appetizer berupa salad. Tahap selanjutnya adalah hidangan utama seperti daging atau seafood. Menu akhir adalah hidangan penutup yang diilustrasikan adalah seperti pudding, kue, es krim, dan jus. Ketiga, tata letak peralatan makan dipraktikan guna memahami secara umum dimana seharusnya peralatan tersebut diletakan. Sebagai contoh, posisi dinner/salad plate yang berada ditengah, diikuti oleh salad \& dinner fork di sebelah kiri dan dinner knife \& spoon di sebelah kanan. Cup and saucer diletakan pada ujung kanan, diikuti dengan water \& wine glass di atasnya. Dessert spoon \& cake fork terletak di atas dinner plate, dan bread plate \& knife disampingnya.

b. Praktik pemanduan wisata di TMII, setelah mengkuti kelas teori teknik pemanduan wisata, siswa/siswi diberi kesempatan untuk mempraktikan teori-teorinya yang sudah diajarkan. Diawali kegiatan, instruktur menjelaskan beberapa daya tarik wisata, seperti nama-nama anjungan yang ada di

$$
\text { Pendidikan }
$$


TMII, sambil mencontohkan bagaimana menjadi seorang pemandu wisata yang efektif. Setelah itu, para siswa mempraktikan mulai dari, mengucapkan salam, memperkenalkan diri dan berkenalan dengan tamu, menjelaskan rangkaian perjalanan (itinerary) dengan singkat, menjelaskan narasi daya tarik wisata dengan jelas, sampai penutupan pemanduan wisata yang mengesankan.

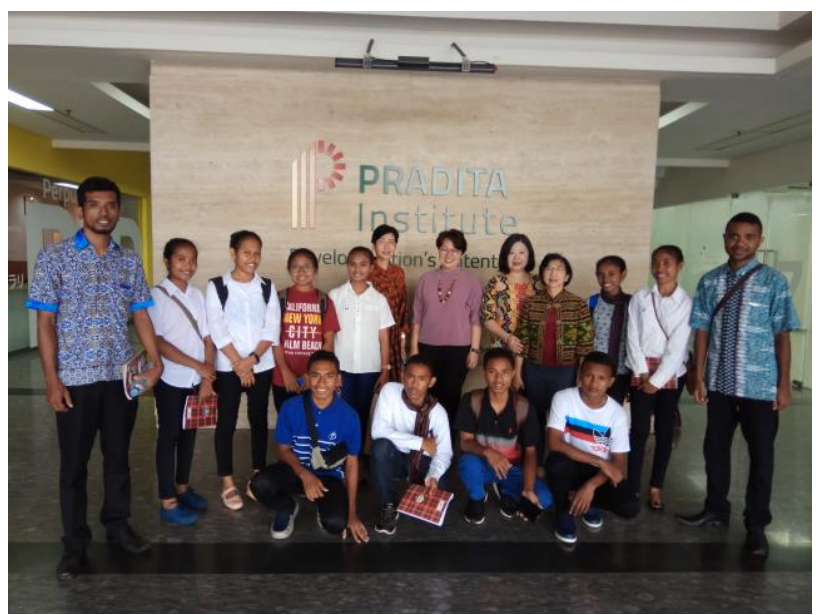

Gambar 1. Siswa, Yayasan Ancop \& Pradita Institute.

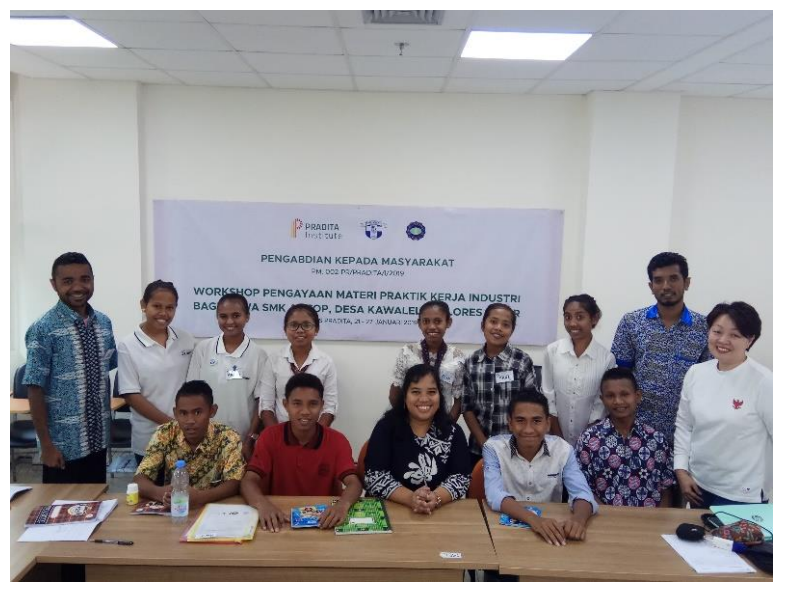

Gambar 2. Siswa dengan Doesn Reservasi \& tarif Dokumen pasasi.

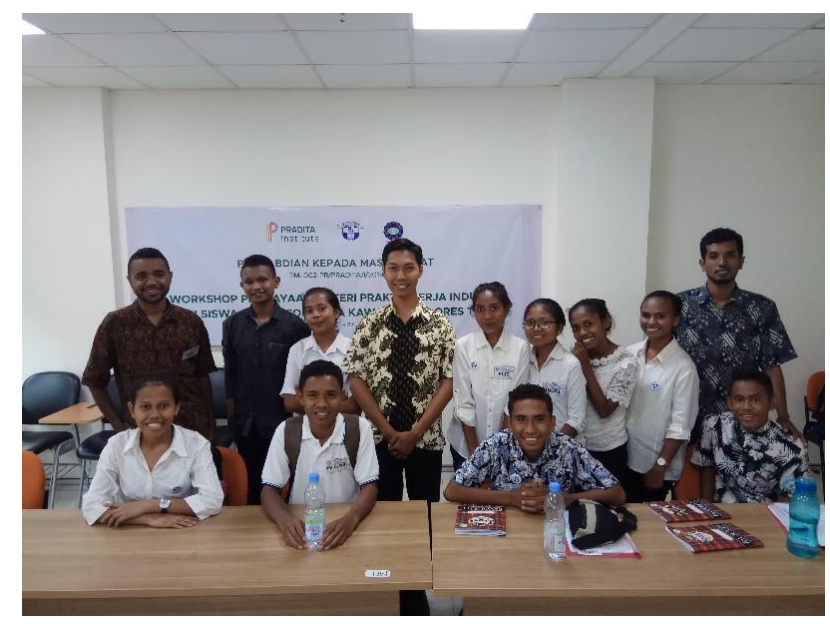

Gambar 3. Siswa dan Dosen Pemanduan Wisata

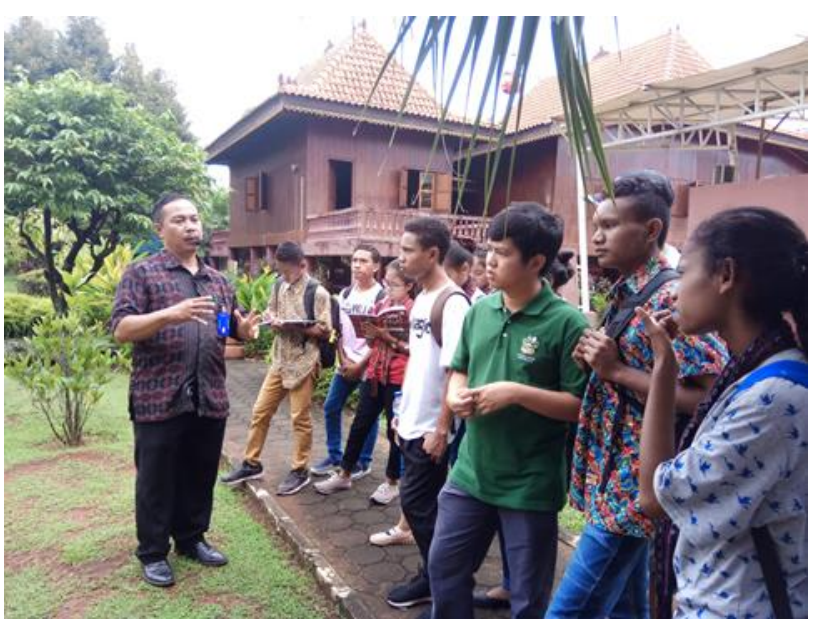

Gambar 4. Praktikum Pemanduan wisata di TMII 


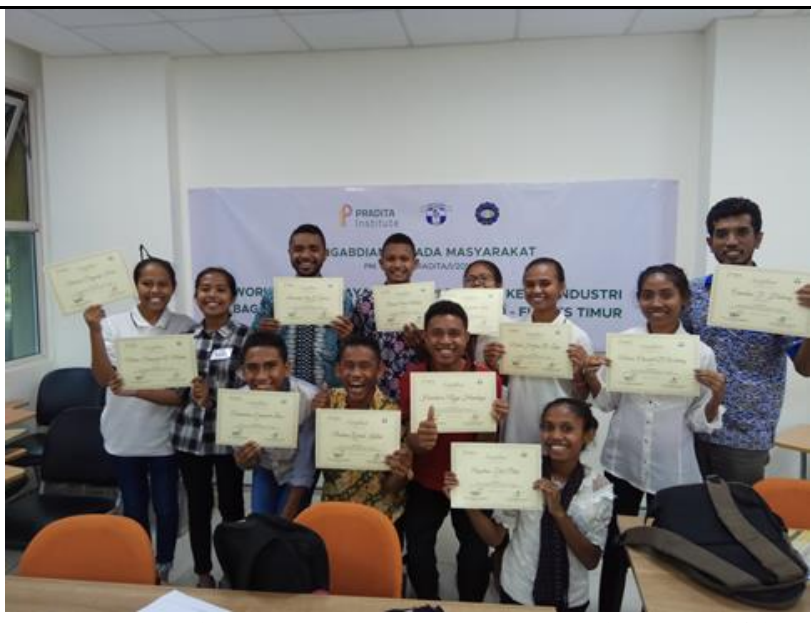

Gambar 5. Siswa SMK ANCOP menerima sertifikat workshop Pradita Institute.

\section{SIMPULAN}

1. Siswa/siswi SMKN ANCOP merasa lebih siap dan percaya diri dalam menghadapi PRAKERIN di sektor pariwisata. Setelah mengikuti kegiatan, mereka menjadi memahami tentang hal-hal yang perlu dipersiapkan, tantangan, dan bagaimana interpersonal/softskill dapat menyesuaikannya. Hal ini dapat dilihat dari banyaknya mereka yang antusias setelah mengikuti semua rangkaian workshop.

2. Praktik pemanduan wisata di TMII telah berhasil dilakukan untuk melihat sejauh mana pembekalan teori di kelas dengan aksi di lapangan. Secara keseluruhan, praktik lapangan menunjukan hasil baik, dimana mereka dapat menjalankannya dengan lancar sesuai dengan teori-teori yang telah diajarkan oleh instruktur dan tim dosen.

3. Peserta merasa puas dan terbekali setelah mengikuti semua rangkaian materi teori dan praktik. Hal ini dapat dinyatakan dengan perasaan puas mereka terhadap kualitas tim pembimbing, materi pembelajaran yang mudah dimengerti, dan praktik pemanduan wisata yang menyenangkan.

4. Keluaran setelah mengikuti pelatihan ini adalah, para siswa setelah lulus diharapkan dapat membangun desanya melalui pemberdayaan masyarakat sebagai pemandu wisata. Selain itu, juga membuka peluang kerja seluas-luasnya bagi orang lain, khususnya di sektor pariwisata.

\section{REFERENSI}

Bisnis.com. (2019). Peran Pengusaha Dibutuhkan untuk Tingkatkan Sertifikasi Pekerja Pariwisata. Diakses pada 19 Juli 2019, dari https://ekonomi.bisnis.com/read/20190206/12/8859 59/peran-pengusaha-dibutuhkan-untuk-tingkatkansertifikasi-pekerja-pariwisata.

Cedefop. (2008). Validation of non-formal and informal learning in Europe: a snapshot 2007. Luxembourg: Publications Office of the European Union.

Cornford, IR. (2005). Vocational education. In: English, L.M. (ed.) International encyclopedia of adult Education. Palgrave Macmillan.

Detik.com. (2018). Kemnaker Target Sertifikasi 1,5 Juta Tenaga Kerja di 2019. Diakses pada $19 \quad$ Juli 2019, dari https://finance.detik.com/berita-ekonomi-bisnis/d4362841/kemnaker-target-sertifikasi-15-jutatenaga-kerja-di-2019.

Grubb, WN., \& Ryan, P. (1999). The roles of evaluation for vocational education and training: plain talk on the field of dreams. Geneva: International Labour Office.

Kotsikis, V. (2007). Educational Administration and Policy. Athens: Ellin.

Zarifis, G. (2000). Vocational education and training policy development for young adults in the European Union: a thematic analysis of the EU trend of convergence towards integration, drawn from the VET policies adopted in three member

$$
\text { Pendidikan }
$$


states. Research in Post-Compulsory Education, 5 (1), 91-113.

Zarifis, G. (2003). Post-school Vocational Training Initiatives for Young Adults in Greece: the case of IEKs (Vocational Training Institutes).
Research in Post-Compulsory Education, 8 (2), 153-178. 